\title{
Mbaima Metlon: Narrativas de mulheres indígenas em situação urbana
}

\section{Mbaima Metlon: urban indigenous women's narratives}

DOI:10.12957/ek.2019.48528

\section{Dra. Aline Rochedo Pachamama - Churiah Puri alinerochedopachamama@gmail.com}

Este artigo é desdobramento da pesquisa realizada para o livro "Guerreiras" que apresenta a realidade de mulheres indígenas em contexto urbano, suas conquistas e desafios. A autora parte do relato e histórias destas mulheres, que guardam também a memória e a cultura de seus povos, para discutir questões fundamentais como a relação colonial, o racismo, a misoginia e a violência que perpassam pesquisas acadêmicas, representações literárias e assim compõem nossos relatos históricos e a lida cotidiana da sociedade brasileira com os povos originários desta terra. Ao mesmo tempo, essas narrativas trazem à tona as formas de resistência e lutas individuais e coletivas dessas mulheres, sua força, sabedoria e o poder da palavra de gerar diálogos, transformações e aprendizados, quando há uma escuta sincera a essas falas de coragem

\section{PALAVRAS-CHAVE Mulheres originárias (indígenas). \\ História oral. Narrativas. Protagonismo}

This paper is an unfolding of the research carried out for the book "Guerreiras" which presents the urban indigenous women's life, their achievements and challenges. The authoress starts from the stories of these women, who keep the memory and culture of their people, to discuss fundamental issues such as the colonial relationship, racism, misogyny and violence that permeate academic research, literary representations and compose our historical approaches and the daily dealings of Brazilian society with the first peoples of this land. At the same time, these narratives bring to light the forms of resistance and individual and collective struggles of these women, their strength, wisdom and the power of the word to generate dialogues, transformations and learning, when there is a sincere listening to these courageous voices.

KEYWORDS Original women (indigenous). Oral history. Narratives. Protagonism 
Mbaima Metlon, na língua do povo Puri, ao qual pertenço, significa " $\mathrm{Mu}$ lher Forte", "Mulher Corajosa". Além de forte e corajosa, a mulher originária é a protagonista da história de nosso país, como mantenedora de sabedoria, artesã e guardiã do idioma, mães, filhas, guerreiras. Para os povos originários brasileiros, a mulher tem a função primordial de preservar sua cultura. Este artigo é desdobramento da pesquisa realizada para o livro "Guerreiras", de minha autoria, que apresenta, além das características supracitadas, a realidade das mulheres que se encontram em contexto urbano, suas conquistas e desafios. Por meio das entrevistas, na escuta das percepções e sentimentos, reconstruímos os fatos (memórias) e registramos as peculiaridades do povo do qual fazem parte.

A pesquisa e o processo de realização das entrevistas tiveram a duração de nove meses. A edição e entrecruzamentos de informações, cinco meses. As informações sobre os povos priorizaram a oralidade e a memória, amparada por bibliografia específica. Os poemas, que antecedem as narrativas no livro, foram traduzidos para o Puri, idioma do meu povo. Algumas frases, que antecedem os relatos, estão no idioma da mulher originária em questão, para que se apresente também a diversidade de línguas. Também, há uma representação do grafismo de cada povo, para mostrar que os Povos Originários no Brasil possuem uma representação gráfica, à parte do idioma, que sempre foi registrado, em seu próprio corpo e em seus artefatos.

Os encontros para a realização das entrevistas ocorreram em espaços públicos, como praças, parques naturais, museus e universidades. Não há um local específico para a reunião de mulheres indígenas na cidade do Rio de Janeiro. Destacamos a oralidade de mulheres que representam outras mulheres. Milhares de mulheres. Anambé - Socorro Borges, Aruaque (conjunto étnico da Amazônia) - Monica Cristina, Guajajara - Namara Gurupy, Guarani - Ara rete - Sandra Benites, Kayapó - Indiara, Kariri - Jane, Krikati - Potira, Maraguá -Liliam, Potiguara -Samehy, Puri -Jecy, Xavante - Julia Muniz, Churiah Puri. São onze povos e doze mulheres, de regiões e estados diferentes, formas culturais distintas, idiomas, histórias, mas tendo em comum a mesma luta e a mesma essência. Apresentaremos algumas dessas narrativas na escrita que segue.

Há uma vasta bibliografia indígena que não foi escrita pelo originário. Tais escritos se apropriam de nossos conhecimentos e saberes, muitas vezes, traduzidos em vários idiomas, menos no idioma daquele que inspirou o registro. $\mathrm{E}$ o autor é sempre o outro. Um Povo, que é Originário, não será mais silenciado em seu próprio território e em seu conhecimento. Então, decidimos pela palavra na primeira pessoa, com exemplificações da nossa oralidade, de peculiaridades dos povos, representados pelas mulheres que aceitaram esse desafio. 


\section{A oralidade de mulheres Originárias}

Os estudos na área de história, utilizando a oralidade de mulheres originárias no tempo presente, ainda não são numericamente significativos. Existem poucas obras de referência publicadas no Brasil e no exterior, que abordem a temática, priorizando o protagonismo originário, por isso, também a importância do livro Guerreiras (PACHAMAMA, 2018). Há uma tendência na historiografia de seguir uma postura excludente perceptível: o "ofício do historiador" é um ofício de homens (brancos) que escrevem a história no masculino. Os campos que abordam são os da ação e do poder masculinos, mesmo quando anexam novos territórios (PERROT, 1998).

No decorrer dos séculos, tanto na literatura quanto em registros históricos, as narrativas generalizam a participação do originário como o "índio", colaborando para afirmar a sua não contemporaneidade, como se fossem um todo homogêneo, iguais entre si e fazendo parte apenas do passado. As abordagens, feitas a partir desses materiais, levaram a concluir que os Povos Originários não fazem parte da sociedade e que essas relações só se deram na época da chegada dos colonizadores ao Brasil. Consolidou-se uma hierarquia científica no campo da História, atribuindo, direta ou indiretamente, aos Povos Originários, a invisibilidade e um lugar de inferioridade, passividade e exclusão. Diante dessas realidades, atualmente, a voz originária ecoa forte e lúcida. A oralidade se mantém como a forma de preservação das línguas e culturas dos Povos Originários e tem a capacidade de revelar a identidade de um povo, seus rituais e o modus operandi de cada grupo. Hoje, a escrita realizada pelo próprio originário se faz igualmente importante.

Destacamos, assim, que a História Oral das Mulheres Indígenas possibilita valorizar a sensibilidade histórica, sinalizando a interpretação da emoção, a felicidade, o medo, a rejeição, dentre outros sentidos que estruturam a vida cotidiana.

Ainda que tratemos a questão da História Oral e História de Mulheres como referência aos estudos da mulher branca, embora esta possua um lugar privilegiado na sociedade, não escapa aos conflitos impostos pela mesma sociedade, em relação à sua condição de mulher. Como sinaliza a autora Graça Graúna (GRAÚNA, 2011), do Povo Potiguara, "é possível dizer - dentro da percepção indígena

1 Povos Originários referem-se às 305 etnias no Brasil atual (que já foram mais de 1000 na época da invasão europeia). A palavra índio, empregada no século XV aos Povos Originários tem origem no nome do rio INDU, do Sânscrito Sindhu, como era conhecido um dos sete rios sagrados da Índia. Acredito que o termo tenha sido usado por conta do fenótipo (cor de pele, cabelo, etc.). Enfim, o nome índio não nos representa. Reduziram a diversidade de povos em apenas uma palavra que não tem referência em nenhuma das Línguas dos Povos Originários. 
- que o indígena não deixa de ser ele mesmo, em contato com o outro - (o não índio)". Assim, penso que a literatura, relacionada à história oral de mulheres, pode contribuir para a reflexão sobre a Mulher originária na história, muito a partir do dado do silenciamento em relação a essa história e seu protagonismo:

\begin{abstract}
Denunciando o genocídio mascarado na esterilização, construindo caminhos contra todo o tipo de preconceito, combatendo as discriminações dentro da própria sociedade em que vivem, representando comitês de saúde, educação e política, compartilhando suas reivindicações o Movimento das Mulheres indígenas, ganhou visibilidade e respaldo a partir da década de 1990. Essa energia está, aos poucos, se fortalecendo em todo país (GRAÚNA, 2011, p.33).
\end{abstract}

Para os povos originários brasileiros, a mulher tem a função primordial de preservar sua cultura. Embora o texto acadêmico tenha exigências próprias, neste escrito, procurei respeitar a dinâmica de oralidade dos Povos Originários. Em diálogo com a parenta Graça Graúna, conversávamos sobre a importância de escritoras originárias (indígenas) e sobre a pesquisa que ela desenvolve, relacionada à literatura dessas mulheres. Foi muito bom ouvir dela a seguinte percepção:

Eu não diria que nós estamos ausentes, eu penso que a presença pode ser maior. Porque a partir do momento que você tem consciência, que eu tenho consciência, que alguns de nossos parentes tem consciência, de nosso papel, como escritora. As nossas irmãs narradoras, que vivem nas comunidades, afastadas ou em centros urbanos, mantém o ponto de vista da terra, de quem está no pé no chão. Como escritoras, ainda que sejamos três, quatro, cinco...nós fazemos barulho. Nós marcamos a nossa passagem no planeta, e isso é importante. Eu vejo que há um acanhamento da mulher indígena como escritora, da mulher indígena conduzindo a fala. O bom seria se a fala indígena fosse tanto de homens, mulheres, adolescentes de crianças, de idosos. Cada um tem uma maneira de dizer sobre sua cultura. Seja por meio da pintura, do manejo de construir uma esteira, um colar, de dançar, de caminhar... tanta coisa (diálogo com Graça Graúna registrado por Aline Rochedo Pachamama em 23 de janeiro de 2018). 


\section{O coração desta terra, chamada Brasil, é coração de Mulher Originária.}

A Mulher Originária gerou o povo que insiste em esquecer sua origem. Tratou de modelar seu corpo; em seu ventre, cantou cantigas de seus ancestrais, em idiomas nossos, e disse o quanto podem ser felizes e prósperos, nesta terra de tantas riquezas. Mas, alguns, após nascer, a rejeitaram. O Brasil é o filho que rejeitou sua mãe originária e, por isso, ainda estamos distantes de muitas práticas sociais coletivas e democráticas.

A Mãe, a Mulher Originária, o Povo Originário ainda passa por violência de todas as categorias conhecidas e traz em si aquela dor, que fica impregnada por gerações. E, apesar dessa trajetória triste e difícil de ser expressa em palavras, ainda cantamos, dançamos, contamos contos, trabalhamos, modelamos a argila, cuidamos da terra, da alimentação dos nossos, estudamos, guardamos saberes, crenças e o universo. Escrevemos nossa história em nosso próprio corpo, em grafismos de imagens, símbolos sagrados, em cicatrizes que trazem a luta e até com nosso próprio sangue, como relata Potira Guajajara, presidenta e cofundadora, junto ao seu esposo José Guajajara, do Cesac Cauiré - organização indígena fundada nos anos 1990, na qual desenvolvem atividades de divulgação da cultura dos Povos Originários para indígenas e não indígenas, especialmente para as crianças do entorno. Potira é presente em atos políticos e sociais em prol dos Direitos dos Povos Originários no Rio de Janeiro, inclusive, nas questões referentes à Aldeia Maracanã, uma tentativa de revitalização do antigo Museu do Índio no Rio de Janeiro. Uma luta ainda em processo para que exista um espaço, gerido por originários, que abrigue uma série de atividades dos Povos Originários.

Aconteceu uma história, que eu não gosto de falar porque é muito triste. Invadiram nossa terra e assassinaram meu povo. Na época, minha vó falou que eram fazendeiros.... Tomaram conta da terra, que hoje é uma cidade e poucas pessoas sabem sobre essa história que aconteceu na época. Queimaram a aldeia. Meus avós que contavam a história. Teve um pesquisador, que esteve aqui com a gente, que tinha foto com os meus avôs. Dos meus tios, da minha mãe pequena. Eu nem gosto de falar porque é muito triste. Saber a história da minha mãe é muito duro; ela não gosta de voltar ao local 
porque meus avós foram mortos. Quem se salvou foi só minha avó e a minha mãe porque meu pai tirou ela de lá. E aí ela primeiro foi morar em outra área bem escondida, bem longe da cidade, que hoje é chamada Pirapora (Potira Guajajara, In: PACHAMAMA, 2018, p.100).

Não há mulher Originária (indígena) "pega no laço”! Há a mulher originária que foi e é ameaçada, capturada, violentada, escravizada. Ela é a representação de uma luta silenciosa, que perdura há séculos. Samehy Potiguara já vem correndo há muito tempo de situações conflitantes, a fim de alçar novos e outros horizontes. Seu olhar tranquilo e forte também transmite coragem. Representa os povos Originários em importantes maratonas. Seus pés descalços, ao correr, nos transmitem a relação com a terra e com as forças ancestrais que nela pulsam, guiando nossos passos. Samehy Potiguara, artesã e maratonista relata como superou a violência vivida na juventude.

\footnotetext{
Eu apanhei muito. Não fiquei com marcas no corpo, mas fiquei com marcas na alma! Eu apanhava de pau, de borracha. Podia ficar com cicatriz, mas não fiquei. Mas, na alma, ficaram as marcas. Não foi somente o ato de "bater", foram as palavras que eu ouvi, que me feriram e deixaram cicatrizes. Palavras que eu não quero nem reproduzir aqui. Mas eu luto. Eu estou me curando dessas lembranças. Que parecem um peso! Não vou carregar isso na minha vida! (Samehy Potiguara, In: PACHAMAMA, 2018, p.128).
}

Não somos fósseis, objeto de estudo, objeto sexual, objeto a ser corrompido por pensamentos religiosos, que não são os nossos. Somos a Existência. Nós, Mulheres Originárias e Povo Originário permanecemos firmes porque somos a força que une toda a vida dessa terra Abya Yala² que em nós pulsa. E, por isso, somos Guerreiras. Não por estimularmos a guerra ou os conflitos, mas por defendermos os nossos, as nossas memórias, a ancestralidade e a nossa própria vida em todas as esferas da sociedade, inclusive, a política.

Julia Muniz é professora de artes plásticas e grande divulgadora das culturas de vários povos em escolas da rede pública. Seus alunos são estimulados a desenvolver trabalhos artísticos que trazem as peculiaridades dos Povos Originários.

2 Abya Yala é o nome do nosso continente dado pelo povo Kuna que significa "terra madura", "terra que pulsa', "terra viva" ou "terra em florescimento". 
Militante, esteve presente em vários atos em prol dos direitos indígenas. Em um episódio muito especial de sua vida, acolheu um xavante e toda a comunidade a acolheu. Xavante por escolha do grupo xavante, muito querida entre os do seu povo. Lembra a percepção dos Povos Originários em relação à esfera política:

\footnotetext{
Vocês falam que o que o índio está fazendo aqui eleito, mas, eu pergunto o que o branco está fazendo aqui? Em que o branco me representa? Então, eu tenho que estar aqui para representar as comunidades ribeirinhas, para representar os indígenas. Talvez, se for um negro ou indígena presidente da república um dia, olhe diferenciadamente para as populações. Para as diversas populações, as nações diferentes que existem nesse Brasil todo" (Julia Xavante. In: PACHAMAMA, 2018, p.163).
}

No Brasil, com a implantação da lei 11.645/08, o ensino de Culturas e Literaturas Africanas, Afro-brasileiras e indígenas tornou-se obrigatório nas redes públicas e privadas de todo o território nacional. Ainda é precária e lacunar a sistematização de tais saberes indígenas, em especial, sobre a Língua e o mapeamento de tais informes em bibliotecas e institutos. Quem ensinou às crianças a história do povo que aqui vive, contou a história de outros, não a nossa. Em algumas regiões, é a mulher indígena quem protagoniza a luta pela educação, como a Andreia, cacique do Povo Cariri no Ceará:

Nosso instrumento de luta é também nossa escola. Ela conscientiza. Nós precisamos nos preparar para estar na luta. A nossa escola conta hoje com 187 alunos e funciona nos três turnos: manhã, tarde e noite. Temos desde a educação infantil ao EJA, para jovens e adultos. Em nossa escola, todos os professores são indígenas, totalizando um número de 24 educadores. A maioria deles é formada em Letras, História e Pedagogia. Todos são participantes da nossa luta, desde 2006, a qual nós travamos e fomos buscar conhecimento para repassar aos nossos filhos, o nosso toré, a nossa cultura, as nossas danças. Dentro da escola indígena, nós podemos cantar e dançar, sem ter o medo de represálias. Nossa aldeia também conta com uma equipe de saúde médica, para atender somente os indígenas, o que também é resultado 
de uma luta, de uma conquista, que conseguimos unidos ao movimento estadual do Ceará (cacique Andrea Kariri. In: PACHAMAMA, 2018, p.81).

Os atos de violência, nos dias atuais, em relação aos povos originários, podem ter a conotação de algo que ocorreu no passado. Mas não. Acontecem agora: invasão e apropriação de território; assassinatos; apropriação de conhecimento cultural; a não aceitação do originário como cidadão; a desvalorização de nossa sabedoria; a imposição de religiões em relação à nossa cultura, que não contemplam as nossas crenças, cosmologia e ritos; a exigência de um perfil de "índio", que traduz uma imagem cristalizada do século XVI; a mídia, que deturpa nossos valores e luta; as ofensas ditas; a escola, que ensina que o "índio" está extinto; o 19 de abril", que não é homenagem; o "índio", que virou adereço e não nos representa. Tais pejorativos, muitas vezes, são alimentados pela própria escola. A escola não-indígena ainda não está preparada para a diversidade cultural dos Povos Originários, como relata Potira Guajajara:

Eu fui levar meus filhos para estudar e eles não entenderam que nós somos indígenas e isso não foi respeitado.

Até hoje tem um preconceito porque, na visão deles (do

3 A data foi escolhida em referência ao Primeiro Congresso Interamericano, ocorrido no México, em 1940. A intenção real do Congresso era a apropriação de territórios indígenas, estimulado pela ambição do então presidente mexicano Lázaro Cárdenas del Río. Os Povos Originários recusaram-se a participar em um primeiro momento, sendo apenas notificada a presença de poucas representações, pois as delegações enviadas eram de não indígenas, os "indigenistas". Após algumas reuniões e reflexões, diversos líderes indígenas resolveram participar do evento. Tal participação ocorreu no dia 19 de abril, que posteriormente foi escolhido como o "Dia do Índio". No caso do Brasil, o delegado enviado foi Edgar Roquette-Pinto, não-indígena, além de ter atitudes preconceituosas e colonizatórias. Em 1943, por determinação do então presidente Getúlio Vargas, o dia do índio é instituído:

Legislação Informatizada:

DECRETO-LEI N ${ }^{\circ}$ 5.540, DE 2 DE JUNHO DE 1943

Considera "Dia do Índio" a data de 19 de abril.

O PRESIDENTE DA REPÚBLICA, usando da atribuição que lhe confere o art igo 180 da Constituição, e tendo em vista que o Primeiro Congresso Indigenista Interamericano, reunido no México, em 1940, propôs aos países da América a adoção da data de 19 de abril para o "Dia do Índio",

DECRETA:Art. $1^{\circ}$ É considerada - "Dia do Índio" - a data de 19 de abril. Art. $2^{\circ}$ Revogam-se as disposições em contrário. Rio de Janeiro, 2 de junho de $1943,122^{\circ}$ da Independência e $55^{\circ}$ da República.

No decreto, não se menciona as questões ligadas à proteção de território, direitos ou legitimação de cidadania, salvaguarda das Línguas maternas dos Povos Originários. Apenas que se instituiu o dia do "Índio". 
não-indígena), o indígena é aquele que vive na aldeia, não é aquele que está aqui. Meus filhos nasceram aqui. Uma nasceu na aldeia Maracanã. Nós falamos o tempo todo: EU SOU INDÍGENA. Eu acho que não precisava disso, da discriminação.

$\mathrm{Na}$ escola, foi muito difícil. Eu coloquei minha filha Maynumi na creche e ela começava a cantar e falar as duas línguas. E o pessoal na escola dizia: "Não pode falar assim!" Aí eu tive que ir lá na escola e conversar com a professora, porque ela estava aprendendo a falar e a criança fala igual a gente fala em casa. E como eu falava as duas línguas com ela e cantava, ela fazia a mesma coisa na creche. Comecei a ir lá e dar palestra, cantar junto com as professoras e aí foi melhorando.

Quando ela mudou de escola e eu chego lá, já tinha toda uma questão com outra professora. A minha sobrinha chegou pintada com nosso grafismo e ela falou que não poderia. Como assim? Não pode entrar pintada? A professora disse para a criança: "Ah, você está suja!"

Aí eu falei para minha irmã: "Olha, se você quiser eu vou lá falar com a professora." A minha irmã falou: "Não precisa... vai arranjar confusão."

Então, eu pensei: eu vou colocar minha filha nessa escola! Aí botei lá e com a maior "sorte" ela caiu com a mesma professora. Que era o que eu queria. Coloquei ela toda pintada e mandei para escola.

Aí ela chegou lá e a professora falou: "Ah você está pintada. Você foi a alguma festa?"

Ela disse: "Não! Me pinto direto quando vou para aldeia."

“Mas, você não pode vir pintada. Não é 19 de abril!" 
Aí, eu não fui na professora; cheguei direto na direção, que eu já conhecia, e disse que, se ela não parasse com isso, eu ia entrar com um processo contra ela por discriminação.

Minha filha é indígena! Ela vai chegar, a hora que quiser, pintada. Na Aldeia Maracanã, está sempre pintada. E, se ela não quiser ir pintada, também, ela não vai, mas ela gosta de se pintar.

Então, fui lá, dei uma palestra na sala da Maynumi. Trabalhei as crianças porque tem todo um processo, aquela coisa toda, ensinar a pintar, porque não é uma coisa feia. É bonito (Potira Guajarara. In: PACHAMAMA, 2018, p.103-104).

O preconceito evidencia-se nas formas pejorativas de se referirem a nós, como "coisa de índio", "modelo tupiniquim", dentre outros. Lembramos, ainda, que não somos "índios", não escolhemos essa forma de chamamento. Inclusive, é bom sinalizar que, se quiséssemos o mês de abril como espaço de memória das lutas indígenas, que fosse para rememorar Galdino Pataxó Hã Hã Hãe, brutalmente assassinado, em Brasília, por cinco jovens de alta classe (que atualmente ocupam altos cargos políticos), no dia 20 de abril de 1997, como sinaliza a autora potiguara Graça Graúna:

Não podemos esquecer que um índio foi morto, enquanto dormia, numa parada de ônibus próxima ao prédio da FUNAI, em Brasília, Exposto ao preconceito de cinco jovens de classe média que atearam fogo em seu corpo, o pataxó Galdino foi assassinado na madrugada de 20 de abril de 1997. Galdino estava em Brasília para reivindicar a demarcação do território Pataxó que foi invadido por fazendeiros na localidade de Pau Brasil, na Bahia. (...) essa tragédia retrata a deficiente política de combate aos crimes cometidos contra os povos indígenas. (GRAÚNA, 2011. p.30)

Indiara é uma anciã. Muito conhecida no Rio de Janeiro, está sempre presente em feiras e encontros dos Povos Originários. Tem muito cuidado com sua 
aparência, apresentando-se sempre alegre e colorida. Curandeira, conhecedora de ervas, flores e frutos. Sua tristeza é pela falta de respeito com a qual o indígena ainda é tratado. A invisibilidade de sua importância na sociedade.

Sou do povo kayapó entre Mato Grosso e Belém do Pará. O que sei é que Indiara significa pertencente à água. Eu já estou com 72 anos. Eu sou uma índia curandeira.

A gente sai na rua, chamam a gente de palhaço, de doido. Isso é falta de respeito com os indígenas! Se as pessoas tivessem um pouquinho de consciência, tivessem amor, entenderiam. Pois são os indígenas que conservaram a terra para os brancos. Porque nós fomos os primeiros habitantes. Não adianta dizer que não. Quando veem um indígena, debocham; quando vê um de nós, grita, diz que somos bicho do mato. Nós somos do mato mesmo! Mas respeita (Indiara Kayapó. In: PACHAMAMA, 2018, p.87).

\section{Mulheres Originárias na cidade com o coração na floresta de seu território}

Não somos menos ou mais originárias, se estamos na aldeia ou na cidade. Cada povo tem sua história e os conflitos encontrados nessa história revelam os motivos da nossa atual situação. Estar na cidade, muitas vezes, é a consequência da mata que o invasor consome; do latifundiário, que cria gado e destrói a biodiversidade local (pois o gado nem é um animal da nossa fauna); da atuação do "senhor de engenho", que hoje quer vender soja e invade nossos espaços; da escravidão pela qual passamos ainda no século XXI, quando acadêmicos usufruem de nosso conhecimento em suas "aulas" e acham que é um favor que fazem ao nos convidar ao trabalho didático - sem que recebamos a energia capital em troca da nossa energia de comunicação; a opção de silenciar nossa origem para nos mantermos vivos; entre outras atrocidades.

Nem sempre é escolha do originário estar na cidade; existem os motivos e precisam ser respeitados. Nosso grande desafio é nos manter firmes em nossas tradições e ancestralidade, onde quer que estejamos. Monica Lima, do tronco 
linguístico Aruaque, militante das causas indígenas e sociais, destaca um dado em relação aos originários que vivem nos centros urbanos:

Os indígenas hoje estão na favela (...). As nossas terras foram ocupadas com muita violência e nós somos obrigados a vir para centros urbanos. E também temos que estar aqui para lutar por nossos direitos. Mas, continuamos sendo indígenas. Continuamos com a nossa cultura, nossa identidade, nossa ancestralidade, nossa espiritualidade, nossa cosmologia. (PACHAMAMA, 2018, p.33).

As dificuldades dessa "sociedade não-indígena" em nos aceitar são inúmeras, cruéis e ilícitas. Um país que não valoriza sua origem está condenado a ser submisso. São opostos ao que somos, já que nosso povo é forte, solidário, sábio e livre.

\section{Quem influencia a nossa compreensão histórica?}

É confuso o proceder de algumas pessoas não-indígenas desses tempos conflituosos: defendem a "história do Brasil", ditada por um alemão; consideram que ler Monteiro Lobato não é tendencioso, que ele foi célebre, ainda que sua escrita seja misógina e racista, que tenha criado o Jeca Tatu para ofender os homens da terra e a tia Anastácia definida como sem família, reduzida ao espaço da cozinha, permanentemente atacada pelo deboche de Emília, sua fala só pode ser ouvida após o aval de dona Benta e cuja sabedoria foi resumida ao lugar do folclore. Segundo a historiadora e militante Giovanna Castro, a tradição escravocrata retira de Anastácia a possibilidade de uma história própria. ${ }^{4}$ Defendem a cultura nacional, na matriz de sua religião patriarcal, depreciando mulheres e homens originários que guardaram ensinamentos sobre plantas, astros e curas. Mas ensinam às crianças que papai Noel existe e disponibilizam a elas "Coca-Cola" para beberem no lanche escolar. Escutam música machista, elegem tais compositores e artistas como brilhantes e acham que isso não influencia uma sociedade inteira como a nossa, que canta a violência contra a mulher em festas de aniversário. Elegem representantes políticos que exaltam torturadores e acham normal a morte de mulheres que lutaram pela vida e liberdade, como Marielle Franco.

4 Conversa informal com Giovanna Castro, doutoranda em História e militante do coletivo "Cabeça de Nêga", na ocasião das atividades do 8M-2020 em Juiz de Fora, Minas Gerais. 


\section{Não somos Iracemas!}

Na literatura, José de Alencar praticamente estreou na escrita com "A carta sobre a Confederação dos Tamoios" (1856), na qual delineou o seu projeto literário de como deveria ser escrita uma literatura cujos personagens fossem os indígenas. Iracema (1865), a pesquisa dos costumes e da língua de uma "raça extinta", foi a base como critério de nacionalidade. Os indígenas são figuras tangenciais da narrativa da nacionalidade e já eram representados como raça extinta. $\mathrm{O}$ autor, que ainda havia figurado a morte do indígena, no desfecho de Iracema, com o falecimento da virgem dos lábios de mel e com o nascimento de Moacir, representante de uma nova raça, não mais falou das tradições indígenas como constituidoras da personalidade nacional. Em Ubirajara (1874), os índios formavam nações que não se confundem com a nação brasileira, representando a proto-história do país. Dizem que respeitam o "índio", mas ainda veneram José de Alencar, que nunca favoreceu o conhecimento sobre os Povos Originários; todavia, de uma maneira perversa, criou personagens "protagonistas", fadados à morte no final de seus enredos, e criou uma Iracema, anagrama de América, que até hoje é leitura obrigatória em algumas escolas. Assim, podemos refletir ainda mais a partir do posicionamento de Monica Lima, do grupo linguístico Aruaque:

Nós vivemos numa sociedade machista, patriarcal em que a mulher é violentada o tempo todo, até sem saber, sem sentir. Pela falta de identidade com ela mesma, como mulher. Ela vive numa sociedade machista e se torna refém de ideias machistas. Muitas vezes, ela obedece ou sem perceber pratica atos machistas contra ela mesma e outras mulheres. E eu estou falando isso não no sentido de culpa, mas, por falta de identidade mesmo, no sentido de ... pelo senso comum. As mulheres são silenciadas o tempo todo, são interrompidas.

A violência existe. Nós temos que ter um perfil de beleza e somos usadas como objeto sexual. Querem nos usar, mas não somos objetos. A mulher indígena não é fetiche! Não é mercadoria! Não é carnaval! (Monica do tronco linguístico Aruaque. In: PACHAMAMA, 2018, p.36).

Toda extensão de terras do Brasil era ocupada pelos povos originários. É anacrônico que parcela da sociedade entenda o originário como um cidadão 
“estranho”. Se há originários (indígenas) nas cidades, conclui-se que as cidades invadiram as florestas, as matas, as fontes, os rios, os mares. Se há florestas, ainda, agradeçam aos Povos Originários, que zelam por elas. Se há originários na cidade e eles estudam, utilizam-se da tecnologia, estão nas plenárias de discussões sociais e políticas, essa atuação não é óbvia? Não somos nós os que já viviam aqui antes? Por que ainda insistem em isolar-nos nas imagens pintadas por viajantes? Num país, onde o invasor destruiu e destrói recursos naturais e a sua gente, somos muito insistentes e fortes por continuar.

Entendemos o valor de registros históricos, literários, mas, sem abordar essa complexa discussão, importa ressaltar a predominância das teorias racistas e discriminatórias entre políticos e intelectuais, que, em parcela significativa, concordavam com a ideia da inferioridade dos "índios".

\section{Mulheres Indígenas no tempo Presente}

Ainda que o momento seja de preocupação e violência intensificada aos Povos Originários, ao final do ano de 2018, nas eleições para presidente do país, entre os candidatos, destacamos a presença de Sônia Guajajara, que compôs, junto com Guilherme Boulos, a chapa do PSOL para a Presidência da República. Ainda que não tenha sido contemplada com votos suficientes, foi um momento de grande importância para as mulheres originárias. Sônia Guajajara, à frente da coordenadoria executiva da Articulação dos Povos Indígenas do Brasil (Apib), é uma das lideranças ambientais do país, unificando mais de 305 povos em torno de pautas que combatem os interesses dos setores mais poderosos da sociedade brasileira:

A luta que o MTST faz aqui na cidade é a luta que nós fazemos em nossas aldeias pra garantir nosso território, que é nossa morada, nossa casa. As ocupações da cidade são as nossas retomadas lá no campo. É uma luta só. O que diferencia a gente é o lugar que travamos essa luta. Não podemos mais aceitar as imposições de uma minoria que não representa ninguém, só a si mesma (trecho do discurso de Sônia Guajajara na Conferência Cidadã em 14 de março de 2018). 
Na mesma eleição, em 2018, Joênia Wapichana foi a primeira mulher indígena eleita deputada federal. Joênia Wapichana milita desde 1997, quando se tornou a primeira mulher originária a se formar em Direito, na Universidade Federal de Roraima. Em 2008, tornou-se a primeira indígena a falar no plenário do Supremo Tribunal Federal (STF), defendendo a legalidade da homologação dos limites contínuos da Terra Indígena Raposa Serra do Sol, em Roraima. Após isso, viajou para os Estados Unidos, onde fez mestrado na Universidade do Arizona.

Sou o resultado de sonhos e de investimentos de outras lideranças indígenas que planejaram ver a nós, indígenas, conquistar diversos espaços. Do movimento indígena que luta para conquistar espaços", disse Joênia à Agência Brasil, nesta quarta-feira (11). "Nada para nós foi fácil. Nem alcançar o reconhecimento de nossa terra; nem eu me formar na faculdade de Direito; nem fazer uma defesa no STF e, muito menos, assumir este espaço tão importante e necessário no Congresso. Se sou uma pioneira, é graças aos povos indígenas, ao nosso movimento e aos esforços de cada povo e pessoa que acreditou nisso (Joênia em entrevista à Agência Brasil, 11 de outubro de 2028).

Em 2019, entre os dias 9 e 14 de agosto, ocorreu a $1^{\text {a }}$ Marcha das Mulheres Indígenas em Brasília, que defendeu o tema: "Território: nosso corpo, nosso espírito". A Marcha foi uma conquista e protagonismo de muitas mulheres, pertencentes a diversos povos que lutam diariamente, a fim de dar visibilidade para as suas causas próprias. Foi resultado de uma luta por reconhecimento e espaço dentro dos movimentos indígenas e também perante a sociedade brasileira. Telma Taurepang, coordenadora da UMIAB - União das Mulheres Indígenas da Amazônia Brasileira - foi a primeira coordenadora mulher no Conselho Indígena de Roraima. Telma sinaliza o processo dessa luta:

No ATL (Acampamento Terra Livre) de 2016, aconteceu a primeira plenária de mulheres indígenas. Aquele momento foi um marco histórico para nós mulheres. Esse reconhecimento da luta das mulheres, do nosso protagonismo dentro da Mobilização Nacional Indígena, dentro do país. Em 2017, surge a segunda plenária, 
em que foi homenageada nossa liderança Rosane Kaingang. Na sequência, em 2018, ocorreram três plenárias das mulheres indígenas. Então, isso impulsionou o coletivo, a voz das mulheres indígenas para que realmente acontecesse a $1^{\mathrm{a}}$ Marcha das Mulheres Indígenas. Mas antes disso, lá em 2014, em Campo Grande, surgiu a discussão para que houvesse essa marcha. Esse grupo deu referência à voz das mulheres indígenas em um projeto dentro da ONU. Começaram lá as discussões e o planejamento para essa marcha que vai acontecer. Então essa é uma luta muito grande, em um contexto que vem há muito tempo sendo de muita resistência e que muitas das vezes nos deixam um pouco de lado, quando temos algumas organizações que não reconhecem ou que não nos veem dessa forma positiva dentro do próprio movimento indígena (declaração feita na ocasião da Marcha das Mulheres, Brasília, Agosto de 2018).

A mulher originária hoje representa sua ancestral do passado, pois sempre ocorreu o protagonismo, embora invisibilizado. Nela, há sabedoria e a coragem de seus encantados. Compreender as mulheres Originárias, em seu tempo e lugar na sociedade, é trazer o elemento principal de nossa História. É perceber que, mesmo com o genocídio, que não cessou no século XXI, ainda existem mais de 305 povos originários e mais de 275 línguas diferentes faladas no Brasil. Nossos valores culturais são milenares. As mulheres originárias fazem acontecer sua história.

\section{Para a oralidade, o aprendizado da escuta}

Para nós, Povos Originários, a palavra não tem duplo sentido. A palavra tem a alma de quem fala e escreve. E eu ouso escrever por isso. Para que minha alma esteja pulsante. E para propor reflexão sobre tais atos e construção de memórias e verdades. Não é o tempo de sustentarmos hipocrisias. A palavra de algumas pessoas está rodeada de atrativos, porém, vazia. Palavra que tem alma é como uma flecha. Causa algo que realmente se sente. E esse sentir gera movimento.

Falar é trazer à luz situações desconfortáveis, memórias de dor. Superações. Mas, aprendemos que compartilhar também é um ato de coragem. Para quem fala, é preciso quem ouça. É necessário também aprender a ouvir. Ainda que as 
palavras estejam escritas, são nossas vozes que ecoam, que perpassam o sentido da visão e chegam aos ouvidos. A palavra é Mbaima Metlon: no processo da escuta à escrita e porque eu respeito essas mulheres com as quais dialoguei e que estão há mais tempo nesse caminho do que eu. E a você, pessoa que lê, meu respeito e gratidão por estar ouvindo. Abya Yala em nós, Tsatêh. Schuteh Poteh.

ALBERTI, Verena. História Oral: a experiência do CPDOC. Rio de Janeiro: Fundação Getúlio Vargas, 1990

AMADO, Janaína e FERREIRA, Marieta de Moraes (org.). Usos e abusos da História Oral. Rio de Janeiro, Ed. FGV, 2001, p.14.

BOSI, Ecléa. Memória e Sociedade: Lembrança de Velhos. 2. ed., São Paulo: T.A. Queiroz, 1994. p. 73.

GRAÚNA, Graça. Contrapontos da literatura indígena contemporânea no Brasil. Belo Horizonte: Mazza Edições, 2013.

HALBWACHS, Maurice. A memória coletiva. São Paulo: Centauro, 2006.

MEIHY, José Carlos Sebe Bom. Manual de História Oral. São Paulo: Edições Loyola, 2002.

NORA, Pierre. Entre memória e história: a problemática dos lugares. São Paulo, Projeto História - Revista do programa de estudos pós-graduados em
História e do Departamento de História. v. 10, 1993.

PACHAMAMA. Aline Rochedo. Guerreiras: mulheres indígenas na cidade, mulheres indígenas da aldeia. Pachamama Editora. Rio de Janeiro, 2018.

SALVATICI. Silvia. Memórias de gênero. Reflexões sobre a história oral de Mulheres. In: Revista da Associação Brasileira de História Oral. Volume 8, Número 1, Janeiro-junho de 2005, p. 29-43.

SCOTT, Joan W. História das mulheres. In: BURKE, Peter.(Org.). A escrita da história: Novas Perspectivas. São Paulo: Unesp. 1992.

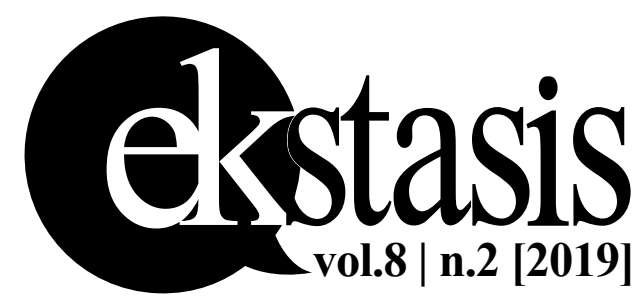

